\title{
Ultra Low Voltage Reflected Electron Energy Loss Spectroscopy
}

\author{
Yusuke SAKUDA ${ }^{1.3}$, Shunsuke ASAHINA ${ }^{1 *}$, Natasha ERDMAN ${ }^{2}$, Takanari TOGASHI ${ }^{3}$, Masato \\ KURIHARA $^{3}$ and Osamu TERASAKI ${ }^{4}$ \\ 1. JEOL.ltd, 3-1-2 Musashino, Akisima, Tokyo 196-8558 JAPAN \\ 2. JEOL USA Inc. 11 Dearborn RD, Peabody, MA, 01960, USA \\ 3. Yamagata University \\ 4. ShanghaiTech University \\ * Corresponding author: sasahina@jeol.co.jp
}

Previous reports about Reflected Electron Energy Loss Spectroscopy (REELS) [1], [2] indicate that the technique is quite similar to EELS in Transmission Electron Microscopy (TEM) which widely used for understanding elements and chemical states in atomic level. However, the EELS technique typically requires a thin electron transparent sample. On the other hand, the REELS is an analytical technique to measure kinetic energy change of electrons resulting from inelastic scattered electrons when a beam of electrons is projected at a few $\mathrm{kV}$ onto the bulk sample. The REELS analyses for the energy loss peaks of electrons provide chemical and structural information on approximately $10 \mathrm{~nm}$ deep of sample surface.

Recently, we have investigated application of REELS in Auger Electron Spectroscopy (AES) especially at low voltage condition such as below $500 \mathrm{eV}$. In such a condition, we expect to detect information from surface in the depth of several $\mathrm{nm}$ at a localized point. In fact, accelerating voltage of AES is able to use at $500 \mathrm{~V}$ as a landing voltage during the routine analysis, since AES is usually aiming to detect Auger electrons in the energy range from 200 to $800 \mathrm{eV}$. Thus, it is necessary to use more than $2000 \mathrm{~V}$ for excitation of Auger electrons. In this study, we have used a deceleration method to reduce the landing voltage in AES down to $100 \mathrm{~V}$ with sample bias voltage. In addition, this deceleration method is a well known method to improve spatial resolution at the low voltage condition ${ }^{[3]}$.

Fig. 1 shows typical REELS spectra of diamond, graphite and carbon nanotube (CNT) at $1000 \mathrm{~V}, 3 \mathrm{nA}$. The (100) surface of diamond single crystal substrate was mechanically polished to reduce the surface roughness under $2 \mathrm{~nm}$. Graphite used as sample was colloidal graphite included in carbon paste. To measure the REELS spectra, graphite and CNT were mounted on a Si wafer. In spectrum of diamond, In spectra of graphite and CNT, two peaks at around $35 \mathrm{eV}$ and $6 \mathrm{eV}$ can be assigned to $\sigma$ bonding and $\pi$ bonding, respectively. Figure 2 shows the REELS spectra of carbon materials measured with lower incident voltage $(200 \mathrm{~V})$. Both $\sigma$ and $\pi$ bonding can be clearly observed even at $200 \mathrm{~V}$ (sample bias -300 $\mathrm{V})$ as landing voltage. According to Kanaya-Okayama formula ${ }^{[4]}$, the interaction volume of carbon at $200 \mathrm{~V}$ is around $2 \mathrm{~nm}$. Usually, the escape depth for electron would be $25 \%$ of interaction volume ${ }^{[5]}$. Therefore, information depth at $200 \mathrm{~V}$ of carbon was calculated as approximately $0.5 \mathrm{~nm}$.

We will discuss details of REELS measurement and also image contrast of low voltage SEM image. We believe that this method will become a new surface analysis method based on the low voltage SEM. 


\section{References:}

[1] Z.L. Wang et al., Surface Science 193 (1988), 501-502

[2] Wolfgang S.M. Werner, SURFACE AND INTERFACE ANALYSIS 35 (2003), 347-353

[3] M. Suga et al, Progress in Solid State Chemistry, 42 (2014) 1-21.

[4] K. Kanaya and S. Okayama, J. Phys. D: Appl. Phys 5 (1972) 43

[5] O. Terasaki et al, JEOL News, 52 (2017)

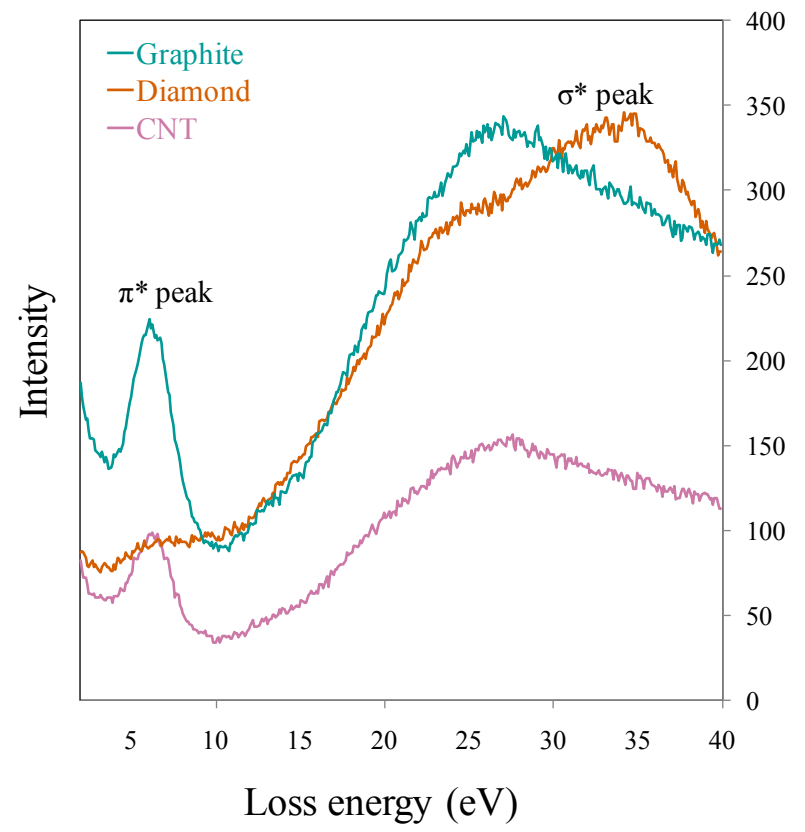

Figure 1. REELS spectra of graphite (green), diamond (orange), and CNT (pink) at $1000 \mathrm{~V}, 3 \mathrm{nA}$.

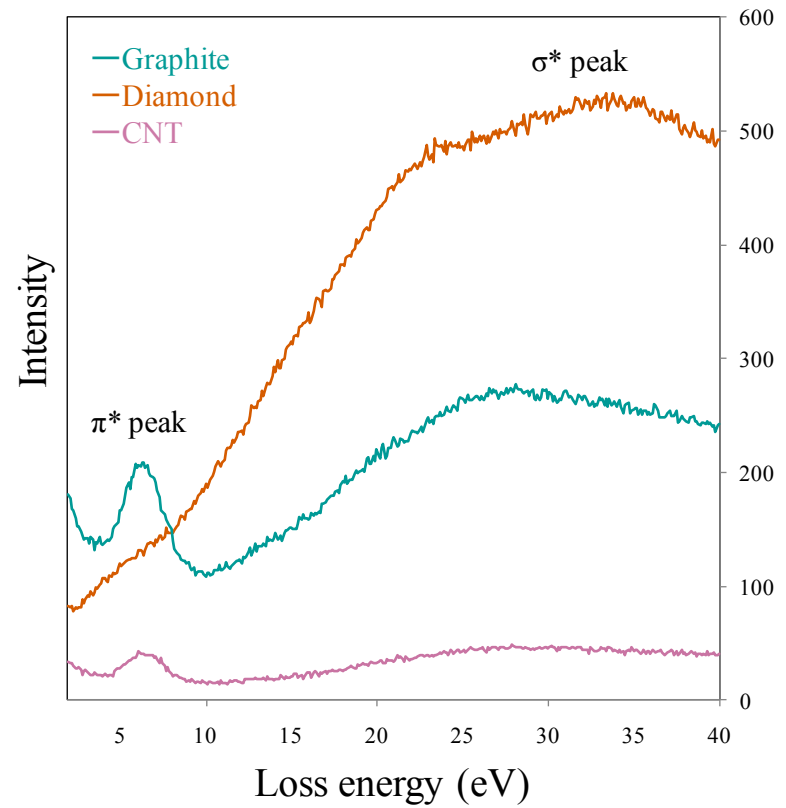

Figure 2. REELS spectra of graphite (green), diamond (orange), and CNT (pink) at $200 \mathrm{~V}, 3 \mathrm{nA}$. 